\title{
Important components of a program for children with medical complexity: An Australian perspective
}

\section{Caregiver perceptions of a complex care service}

\begin{abstract}
Background

Children with medical complexity $(\mathrm{CMC})$ have high care needs, often unmet by traditional healthcare models. In response to this need, the Complex Care Service (CCS) at The Royal Children's Hospital $(\mathrm{RCH})$, Melbourne was created. While preliminary parent satisfaction data were available, we lacked knowledge of how the various components of the expanded service were valued and contributed to overall caregiver satisfaction.
\end{abstract}

Aim

The aims of this study were to 1 ) determine what caregivers value most about the CCS and 2) explore caregiver perceptions of care.

Methods

All caregivers of children enrolled in the RCH CCS in April 2017 were invited to participate. A purposefully designed survey explored caregiver perceptions of care, including: patient quality of care; the extent to which the CCS components added value and satisfaction; and frequency of contact. Participants were also invited to answer open-ended questions and provide general comments.

Results

Responses were received from 53 families (51\%). We found that 24-hour phone advice; coordination of appointments; a key contact; and access to timely information, were the most important components of the service. More than $90 \%$ of caregivers indicated that they were satisfied with care and that the CCS improved their child's quality of care. Coordination, communication, family centred care, quality care and access were emergent themes within comments.

This is the author manuscript accepted for publication and has undergone full peer review but has not been through the copyediting, typesetting, pagination and proofreading process, which may lead to differences between this version and the Version of Record. Please cite this article as doi: $10.1111 /$ cch.12721

This article is protected by copyright. All rights reserved. 
Conclusion

This study provides important information regarding the design and operation of services for CMC throughout Australia and further afield. Our findings highlight the importance of the key contact and family-centred care. This has implications for practice, as maintaining service quality as the CCS expands and is implemented more widely is a major sustainability challenge. It is crucial that we have a detailed understanding of what elements are required to support effective care coordination, to achieve successful implementation on a larger scale.

\section{BACKGROUND (1500)}

Changing medical care has resulted in growing numbers of children with medical complexity (CMC). $\mathrm{CMC}$ have one or more chronic conditions, have substantial functional limitations and are medicallyfragile. They have high care needs that are often not met by traditional healthcare models (Cohen, Berry, Sanders, Schor, \& Wise, 2018). These children represent a growing percentage of the paediatric population, who disproportionately contribute to paediatric healthcare expenditure. In Australia, they account for approximately $14 \%$ of all childhood hospital admissions and one-third of total expenditure for childhood admissions (Srivastava, Downie, Hall, \& Reynolds, 2016). Over 75\% of all admissions among Australian children with medical complexity take place in paediatric hospitals. Frequent healthcare encounters are also associated with negative implications for children and their families, including disruptions to family life, time off work and increased financial pressures due to out-of-pocket costs (Kuo, Cohen, Agrawal, Berry, \& Casey, 2011).

The number of healthcare professionals, care settings and treatments that underpin management of CMC leads to challenges for families in coordinating their children's care (Hillis, Brenner, Larkin, Cawley, \& Connolly, 2016). Dedicated, structured programs for CMC have been established at many children's hospitals to coordinate the care needs of this group (Adams et al., 2019; Cohen et al., 2010; D. Z. Kuo et al., 2016). Typically, these programs involve dedicated care coordinators working with families to assist with integration and communication between the many practitioners and services involved in their child's care. There is growing evidence that improving care for this 
population results in improved utilisation of healthcare resources and high levels of parent satisfaction (Berry, Agrawal, Cohen, \& Kuo, 2013; Cohen et al., 2010; Cohen, Jovcevska, Kuo, \& Mahant, 2011; Cohen et al., 2012; Kuo et al., 2016; Peter et al., 2011)

In response to this growing need, the Complex Care Service (CCS) at The Royal Children's Hospital (RCH) in Melbourne was created, piloted and evaluated in 2014/2015. The main goal of this service was to establish an integrated and coordinated approach to the care and treatment of children with chronic and complex medical needs in partnership with their families. There were three key components to the pilot service: care coordination, access to services and family partnership. A Clinical Nurse Consultant (CNC) was employed to work alongside families. Results from the RCH CCS pilot study, involving 20 children, suggested that in the 12 months following enrolment in the service, children experienced less nights in hospital and fewer emergency department presentations, compared to the 12 months prior to enrolment (Stephens, Mountford, \& Bryan, 2015). Notably, parent satisfaction with their experience of care from the $\mathrm{RCH}$ increased from $48 \%$ pre-enrolment to $77 \%$ post.

Following the pilot, the CCS expanded in 2015 to include approximately 100 children in the service. While there was preliminary data on the level of parent satisfaction with the piloted service, we did not have sufficient knowledge of the relative value and importance of the various components of the service nor parent satisfaction once the service expanded. Exploring what is most important to caregivers will aid our understanding of the needs of families of CMC and inform the future development of services for $\mathrm{CMC}$ at both the $\mathrm{RCH}$ and health services across Australia.

\section{Aims}

The aims of this study were to 1 ) determine what caregivers value most about the CCS service at the $\mathrm{RCH}$ and 2) explore caregiver perceptions of care.

\section{METHODS}

Participants

All caregivers of children enrolled in the CCS at the RCH by April 2017 were invited to participate. 
Study data were collected and managed using REDCap (Research Electronic Data Capture) tools hosted at the Murdoch Children's Research Institute (Harris et al., 2009). A link to a REDCap survey was sent electronically via email to all caregivers who had previously provided a valid email address. An information statement was included at the beginning of the survey and participants were required to indicate they had read it before they could proceed. The Information Statement explained that the child's electronic medical record (EMR) would be accessed to obtain further information about the child's demographics and medical condition. If a valid email address was not available, caregivers were contacted by telephone and had the option of providing an email address and completing the survey online, or completing it over the phone.

Survey

A purposefully designed survey was used to explore caregiver perceptions of care and included questions regarding: frequency of contact with the CCS; the extent to which the CCS improved the quality of care of patients; satisfaction with the CCS; the extent to which the components of the CCS added value to the care of patients; and likelihood of recommending the service to other families. Participants were invited to answer open-ended questions about what the CCS did well and what could be improved, as well as provide general comments.

The survey was designed by staff who were working in the CCS and was piloted with staff and colleagues for readability and face validity. The survey was only available in English, due to limited resources (see Appendix 1).

\section{Audit}

Problem list data for each child, whose family completed the survey, were extracted from the hospital Electronic Medical Record (EMR) 'Epic', using a report designed by the EMR research team. Diagnoses were categorised by system and where appropriate, combined within a broader diagnostic label (e.g. complex congenital heart disease) in order to ascertain the rates with which certain chronic conditions recurred within our sampled population. Acute medical conditions, for example fever, were not included in the final problem list.

Analyses

This article is protected by copyright. All rights reserved. 
Descriptive variables included the age, gender and clinical conditions of the child. Caregiver characteristics included primary carer, age of the responding caregiver, marital status, education level attained, employment status, language spoken at home and postcode. Items rated on 5- or 7point scales were recoded to binary variables. Data were analysed descriptively using STATA version14.2 (StataCorp, College Station, TX, USA). Descriptive demographic statistics were compiled from the raw data.

Socioeconomic status was estimated using postcode which was linked to the related Socio-Economic Indexes for Areas (SEIFA) Index of Relative Socio-economic Advantage and Disadvantage (IRSAD) deciles published by the Australian Bureau of Statistics (ABS, 2011). The IRSAD ranks geographic areas according to their socioeconomic characteristics based on five-yearly census data. SEIFA IRSAD deciles were combined into quintiles with quintile 1 being the most disadvantaged and quintile 5 being the most advantaged.

Qualitative data were analysed thematically. The comments were coded iteratively initially, and then re-coded, until higher order themes emerged.

\section{Ethics}

Ethics approval was obtained from the RCH Human Ethics Research Committee (36338A). RESULTS

In April 2017, 104 patients were enrolled in the CCS and 103 were deemed eligible to participate in this study. One family was excluded in view of child residing in out of home care. Surveys were sent electronically to 88 families for whom an email address was on record. The remaining 15 families were contacted by telephone and offered to have the survey emailed or completed over the phone. Responses were received from 53 families (51\%).

The characteristics of the respondents and children are presented in tables 1 and 2 . For the majority (92.2\%) of children, the mother was the primary carer. The median age of carers was 37 years (IQR 33-41). Most respondents' (75.5\%) primary language was English and almost half (49.1\%) had a tertiary degree. Most primary caregivers (71.7\%) were not in paid employment. There was representation from across the SEIFA IRSID quintiles, with $19 \%(n=10)$ of respondents residing in neighbourhoods with the lowest SES classification (SEIFA IRSAD quintile 1$)$ and $21 \%(n=11)$ residing 
in neighbourhoods that have the highest SES classification (SEIFA IRSAD quintile 5). The largest proportion (32\%; $n=17$ ) were residing in quintile 4 neighbourhoods.

Of the children included in the survey (Table 2), most were male (60.4\%) and first born (49.1\%). Over half $(52.8 \%)$ of the children were aged between 1 to 4 years, with relatively few aged less than 1 year or greater than 10 years ( $7.6 \%$ and $9.5 \%$ respectively). The five most common medical problems for children in the study were feeding problems $(n=32,60.4 \%)$, cardiac lesions (including complex congenital heart disease) ( $n=28,52.8 \%)$, genetic syndromes $(n=20,37.7 \%)$, cerebral palsy $(n=17,30.1 \%)$ and developmental disability $(n=17,30.1 \%)$. The most common medical technology was gastrostomy/feeding tube (60.4\%); the next most common being tracheostomy (17\%) (Table 3 ).

\section{QUANTITATIVE RESULTS}

Respondents reported high levels of contact with the CCS, with almost half (49.1\%) having at least weekly contact with the CCS (Table 4). The large majority (90.2 \%) of respondents indicated that the CCS improved quality of care for their child. Respondents were generally satisfied with the service with over $90 \%$ reporting they were very/somewhat satisfied with the CCS (Figure 1).

Respondents were asked to rate the value of the components of the CCS using a 7-point scale, from "to a small extent" to "a very great extent". The seven points on the scale were then reduced to two: "to a fairly great extent or more" and "to a moderate extent or less". Figure 2 presents the components ranked in order of most highly valued; 24 -hour phone advice (100\%), coordination of appointments (98.1\%) followed by access to a key contact and provision of timely information (94.1\%).

\section{QUALITATIVE RESULTS}

The themes that emerged from the analysis of the comments were categorised into: Coordination; Communication; Family-centred care; Quality of Care; and Access (see Table 5).

\section{Coordination}

Most caregivers commented on the value of the appointment coordination:

"...But the best thing is the co-ordination of appointments...so I'm not there every day."

This article is protected by copyright. All rights reserved. 
The CCS's role in streamlining care was another key theme that emerged as part of the coordinating role. Of particular value was the coordination of presentations to the Emergency Department and facilitating admissions.

The benefit of a single, trusted point of contact emerged as an important subtheme:

"Having someone to call when my child becomes unwell to discuss a plan on what to do has become something that I rely heavily on."

Respondents valued the support of a key contact "who knows your child and who knows what they're talking about". However, some respondents identified that there wasn't the same level of support when their key contact was away. Many respondents expressed a desire for their key contact to be more available, although acknowledging that this may be unfeasible.

Caregivers considered the overseeing role the CCS, including monitoring of plans made on discharge or during appointments and following up results, to be essential. Respondents reported that the CCS ensured that key details were not overlooked.

\section{Communication}

Almost all respondents commented on communication as a central theme. Improved communication between the $\mathrm{RCH}$ and caregivers was valued by most and described as timely, useful and of a high standard. Respondents described that being able to communicate with the CCS validated their concerns and avoided unnecessary presentations:

"They listen to me. Before [CCS] they used to ignore me. Now I feel heard. They take me seriously. My son nearly died so many times."

Facilitating collaboration through improved communication between professionals - both among $\mathrm{RCH}$ medical teams and between the hospital and community practitioners - also emerged as an important component. Families valued the role the CCS played in ensuring all teams involved in their child's care were informed regarding hospital admissions and changes to treatment plans.

\section{Family Centred}

This article is protected by copyright. All rights reserved. 
The support provided by the CCS was a theme that emerged for almost all families, important for reducing stress for carers:

"I make one call or email regarding issues [and] the stress of managing my child is reduced."

Phone support particularly was highlighted as "crucial for extra advice or as a sounding board". Many families valued being able to discuss their child's condition.

The relationships that families developed with the CCS team and their key contact were fundamental to the family centred nature of the service. Families identified that they were comfortable to approach the CCS with any issues and appreciated reassurance provided. Many families commented on the level of respect and care shown, not simply for the medical condition but for the overall wellbeing of the family and child. Some families expressed concern about this aspect of the service being compromised if the CNCs' workload increased.

The advocacy role that the CCS played was identified by some families as being valuable, to help "negotiate things at medical appointments". Some caregivers felt that their needs and wishes were more successfully communicated with the support of the CNC.

\section{Quality Care}

The CNCs' knowledge and skills were highly valued by most families. Parents welcomed their understanding of the complexity of the children's conditions and range of needs. Many parents attributed improved outcomes to the CNC's availability and "appropriate" advice.

Trust in the CCS and reliance on the advice provided, emerged as a common theme. However, the advice was not considered as useful when provided by a CNC who was not familiar with the child or family. Generally, parents regarded the CCS staff to be professional and committed and many commented on the overall positive impact of the service.

"I am extremely grateful that we are under this team, just knowing they are a phone call away when we are in trouble has been life changing for us."

\section{Access}

This article is protected by copyright. All rights reserved. 
A common theme to emerge was the value of the CCS being available at all times. Parents valued being able to communicate in person with the service "24 hours a day". Many parents suggested that the service needed to expand so that the CNCs could be more available to their allocated families:

"Sometimes I'm worried that I'm taking up too much of their time, as the complex care nurses can be very busy with other families. So perhaps more staff so that they are not as busy."

Other families suggested expanding the service so that more families could benefit, and providing the service earlier in a patient's journey.

\section{DISCUSSION}

This study has highlighted that for caregivers of CMC, the most important components of the CCS were: 24-hour phone advice; coordination of appointments; a key contact; and access to timely information. Overall, levels of satisfaction with the service were high, with $92.2 \%$ of caregivers indicating that they were very or somewhat satisfied with care. Further, over $90 \%$ of participants perceived that the CCS improved the quality of their child's care. Coordination, communication, family centred care, quality care and access were emergent themes in caregivers' comments.

The majority of caregivers (90.2\%) who responded considered that the CCS improved the quality of care their child received. This finding was mirrored in the comments from caregivers, with reports that access to the service, and in particular access to knowledgeable nursing staff, improved their child's quality of life. These findings are consistent with other studies examining the impact of care coordination services in North America (Cohen et al., 2012; Simon, Cawthon, Popalisky, \& MangioneSmith, 2017). A cluster randomised controlled study carried out in the U.S. (Simon, Cawthon, et al., 2017) found that exposure to a hospital based comprehensive case management service generally improved quality of care (such as improvements in reports of receiving help with coordinating multiple providers, in the getting-needed-care-quickly scores, and in the health care quality global ratings). The authors concluded that the service improved quality of care by improved access to care, supplies and services that may not have been available prior to involvement with the service. In other words, these services are meeting previously unmet health care needs.

This article is protected by copyright. All rights reserved. 
There are many reports of services for CMC addressing unmet health care needs (Aboneh \& Chui, 2017; Kuo et al., 2014; Simon, Whitlock, et al., 2017) and the importance of this role was supported by caregiver comments in our study. The way in which the RCH CCS addressed unmet health care needs was evident across a number of themes. Caregivers in our study reported that the CCS addressed gaps in care by providing access to medical advice 24 hours a day, a key contact, coordination and overview of care, and improved communication, which all ensured timely, improved management. These qualitative findings were further corroborated by three of the four CCS components classified as most important for caregivers: 24-hour phone advice, availability of a key contact, and access to timely information. Moreover, the frequency of contact that caregivers had with the CCS in this study reflects the high level of need that cannot easily be met by clinicians alone.

These components of the CCS, identified by caregivers as being the most important, are likely indicators of what contributed to the very high level of caregiver satisfaction with the CCS. In our study, the importance of the key contact emerged as both a main qualitative and quantitative finding and is consistent with other studies (Dewan \& Cohen, 2013; Hillis et al., 2016). 'Carecoordinators' were identified as pivotal to reducing caregiver strain and depression and increasing caregiver satisfaction (Edelstein, Schippke, Sheffe, \& Kingsnorth, 2017). It is not surprising that reducing caregiver stress is associated with improved satisfaction. Edelstein et al (2017) also found that access to an enhanced care coordinated model was associated with reports of decreased stress and better family functioning. Key aspects identified by Edelstein included family centred care, shared care plans, timely referrals, care coordination activities and centralised information. While we did not measure caregiver stress, throughout the qualitative themes caregivers identified the benefit of the CCS in reducing their stress levels and providing 'piece of mind'. In particular, the coordination role, the trusting relationships with the key contacts and the family centred nature of the service were identified as reducing stress.

Care coordination has been identified as a central feature of care delivery for CMC (Adams et al., 2019; American Academy of Pediatrics, 2014; Glader, Plews-Ogan, \& Agrawal, 2016; Kuo \& Houtrow, 2016; Kuo, McAllister, Rossignol, Turchi, \& Stille, 2018; Ziring et al., 1999), with a 'hub and spoke' model adopted by many - the family and key coordinator at the hub and relationships with various specialists and community agents representing the spokes (Glader 2016). The challenge is that care 
coordination is a broad concept that can be interpreted differently by services and users of those services. Kuo et al (2018) discuss four characteristics of care coordination as described in a policy statement by the American Academy of Pediatrics (American Academy of Pediatrics, 2014; Antonelli, McAllister, \& Popp, 2009): 1) family-centredness 2) planned, proactive, and comprehensive focus 3 ) promotion of self-care skills and independence; and 4) emphasis on cross-organisational relationships. They go on to describe that effective care coordination produces care integration, being "the seamless provision of health care services, from the perspective of the patient and family, across the entire care continuum. It results from coordinating the efforts of all providers, irrespective of institutional, departmental, or community-based organizational boundaries" (Antonelli et al., 2009).

To achieve care integration - the desired outcome for CMC (Adams et al., 2019; Kuo et al., 2018) - it is thus essential to provide comprehensive care coordination. While there are many different activities that can be performed under the title of care coordination, caregivers in our study did identify components that can all be mapped to the AAP framework for care coordination (American Academy of Pediatrics, 2014). At the time of the study, the CCS was delivering care coordination that was family-centred and used a partnership approach that supported proactive planning of care (Adams et al., 2019). What did not emerge in our qualitative findings was whether the CCS addressed social determinants of health (finances, employment, housing, food security, transportation etc), a component that has been identified by Kuo et al (2018) as integral to optimal care coordination.

There are limitations to this study. The generalisability of the findings may be limited as the response rate was $53 \%$ and there may be unmeasured selection bias. Perception of care for non-participating caregivers may have been very different and there is evidence that non-responders in patient satisfaction surveys are likely to have worse health status than the population average and be less satisfied with medical care (Rubin, 1990). The survey was only administered in English as it was beyond the scope of the study to translate the survey or employ interpreters. Ethnic minority groups repeatedly report lower levels of patient satisfaction (Mazurenko, Collum, Ferdinand, \& Menachemi, 2017) thus excluding families from non-English speaking backgrounds could have introduced bias. While we do not have demographic data on the non-responders, a quarter (24.5\%)

This article is protected by copyright. All rights reserved. 
of responders spoke a language other than English as their main language. Further study is warranted to explore the needs and perceptions of care of non-English speaking families.

While high response rates are preferable, response rates of $50 \%$ in patient satisfaction surveys are considered 'quite high' (Sitzia \& Wood, 1997). Second, in those families who had an email address on record there was no personal contact, which is known to reduce response rates (Sitzia \& Wood, 1997). Thus our response rate to an electronic patient survey is not unexpected. Finally, the survey extended beyond 'satisfaction' and explored caregiver perception of care, applying triangulation of qualitative and quantitative data that enables different dimensions of the same phenomenon to be captured (Leung, 2015).

Despite the limitations, this study provides some important information for those involved in the design and running of services for $\mathrm{CMC}$ in hospitals throughout Australia and further afield. This study has identified priorities for families from our CCS, highlighting the importance of the key contact and family centred care. The frequency of contact with the CCS further illustrates the high needs of families and children with CMC. These findings have implications for practice, as maintaining service quality as it expands and is implemented more widely is a major sustainability challenge (Ronis, Grossberg, Allen, Hertz, \& Kleinman, 2018). It is crucial that we have a detailed understanding of what elements are required to support effective care coordination, including adequate staffing, training and infrastructure, to achieve successful implementation on a large scale (Hillis et al., 2016). Further studies are warranted to continue to explore how partnerships with all families, including culturally and linguistically diverse, can be optimised.

\section{ACKNOWLEDGEMENTS}

(Title page)

This article is protected by copyright. All rights reserved. 


\section{KEY MESSAGES}

1. Children with medical complexity (CMC) have high care needs, often unmet by traditional healthcare models.

2. These children represent a growing percentage of the paediatric population

3. We need to understand priorities for caregivers of $\mathrm{CMC}$ to inform the future development of services for $\mathrm{CMC}$

4. This survey highlights the importance of the key contact and family-centred care.

5. This has implications for practice, as maintaining quality as services for $\mathrm{CMC}$ expand and are implemented more widely is a major sustainability challenge.

\section{REFERENCES}

Aboneh, E. A., \& Chui, M. A. (2017). Care coordination, medical complexity, and unmet need for prescription medications among children with special health care needs. Res Social Adm Pharm, 13(3), 524-529. doi:10.1016/j.sapharm.2016.05.043

ABS. (2011). Socio-Economic Indexes for Areas. Retrieved from http://www.abs.gov.au/websitedbs/censushome.nsf/home/seifa

Adams, S., Nicholas, D., Mahant, S., Weiser, N., Kanani, R., Boydell, K., \& Cohen, E. (2019). Care maps and care plans for children with medical complexity. Child Care Health Dev, 45(1), 104-110. doi:10.1111/cch.12632

American Academy of Pediatrics. (2014). Patient- and family-centered care coordination: a framework for integrating care for children and youth across multiple systems. Pediatrics, 133(5), e1451-1460. doi:10.1542/peds.2014-0318

Antonelli, R. C., McAllister, J. W., \& Popp, J. (2009). Making care coordination a critical component of the pediatric health system: a multidisciplinary framework. Retrieved from New York, NY:

Berry, J., Agrawal, R., Cohen, E., \& Kuo, D. (2013). The landscape of medical care for children with medical complexity. Retrieved from Alexandria, VA, Overland Park, KS:

Cohen, E., Berry, J. G., Sanders, L., Schor, E. L., \& Wise, P. H. (2018). Status Complexicus? The Emergence of Pediatric Complex Care. Pediatrics, 141(Suppl 3), S202-s211. doi:10.1542/peds.2017-1284E

Cohen, E., Friedman, J. N., Mahant, S., Adams, S., Jovcevska, V., \& Rosenbaum, P. (2010). The impact of a complex care clinic in a children's hospital. Child: Care, Health and Development, 36(4), 574-582. doi:10.1111/j.1365-2214.2009.01069.x

Cohen, E., Jovcevska, V., Kuo, D. Z., \& Mahant, S. (2011). Hospital-based comprehensive care programs for children with special health care needs: a systematic review. Arch Pediatr Adolesc Med, 165(6), 554561. doi:10.1001/archpediatrics.2011.74

Cohen, E., Lacombe-Duncan, A., Spalding, K., Maclnnis, J., Nicholas, D., Narayanan, U. G., . . Friedman, J. N. (2012). Integrated complex care coordination for children with medical complexity: a mixed-methods evaluation of tertiary care-community collaboration. BMC Health Services Research, 12, 366. doi:10.1186/1472-6963-12-366

Dewan, T., \& Cohen, E. (2013). Children with medical complexity in Canada. Paediatrics \& Child Health, 18(10), 518-522.

Edelstein, H., Schippke, J., Sheffe, S., \& Kingsnorth, S. (2017). Children with medical complexity: a scoping review of interventions to support caregiver stress. Child Care Health Dev, 43(3), 323-333. doi:10.1111/cch.12430 
Glader, L., Plews-Ogan, J., \& Agrawal, R. (2016). Children with medical complexity: creating a framework for care based on the International Classification of Functioning, Disability and Health. Developmental Medicine and Child Neurology, 58(11), 1116-1123. doi:10.1111/dmcn.13201

Harris, P. A., Taylor, R., Thielke, R., Payne, J., Gonzalez, N., \& Conde, J. G. (2009). Research electronic data capture (REDCap) - A metadata-driven methodology and workflow process for providing translational research informatics support. J Biomed Inform, 42(2), 377-381.

Hillis, R., Brenner, M., Larkin, P. J., Cawley, D., \& Connolly, M. (2016). The Role of Care Coordinator for Children with Complex Care Needs: A Systematic Review. Int J Integr Care, 16(2), 12. doi:10.5334/ijic.2250

Kuo, D. Z., Berry, J. G., Glader, L., Morin, M. J., Johaningsmeir, S., \& Gordon, J. (2016). Health Services and Health Care Needs Fulfilled by Structured Clinical Programs for Children with Medical Complexity. J Pediatr, 169, 291-296.e291. doi:10.1016/j.jpeds.2015.10.010

Kuo, D. Z., Cohen, E., Agrawal, R., Berry, J. G., \& Casey, P. H. (2011). A national profile of caregiver challenges among more medically complex children with special health care needs. Archives of Pediatrics \& Adolescent Medicine, 165(11), 1020-1026. doi:10.1001/archpediatrics.2011.172

Kuo, D. Z., Goudie, A., Cohen, E., Houtrow, A., Agrawal, R., Carle, A. C., \& Wells, N. (2014). Inequities in health care needs for children with medical complexity. Health Aff (Millwood), 33(12), 2190-2198. doi:10.1377/hlthaff.2014.0273

Kuo, D. Z., \& Houtrow, A. J. (2016). Recognition and Management of Medical Complexity. Pediatrics, 138(6). doi:10.1542/peds.2016-3021

Kuo, D. Z., McAllister, J. W., Rossignol, L., Turchi, R. M., \& Stille, C. J. (2018). Care Coordination for Children With Medical Complexity: Whose Care Is It, Anyway? Pediatrics, 141(Suppl 3), S224-s232. doi:10.1542/peds.2017-1284G

Leung, L. (2015). Validity, reliability, and generalizability in qualitative research. J Family Med Prim Care, 4(3), 324-327. doi:10.4103/2249-4863.161306

Mazurenko, O., Collum, T., Ferdinand, A., \& Menachemi, N. (2017). Predictors of Hospital Patient Satisfaction as Measured by HCAHPS: A Systematic Review. J Healthc Manag, 62(4), 272-283. doi:10.1097/jhm-d$15-00050$

Peter, S., Chaney, G., Zappia, T., Van Veldhuisen, C., Pereira, S., \& Santamaria, N. (2011). Care coordination for children with complex care needs significantly reduces hospital utilization. Journal for Specialists in Pediatric Nursing: JSPN, 16(4), 305-312.

Ronis, S. D., Grossberg, R., Allen, R., Hertz, A., \& Kleinman, L. C. (2018). Estimated Nonreimbursed Costs for Care Coordination for Children With Medical Complexity. Pediatrics. doi:10.1542/peds.2017-3562

Rubin, H. R. (1990). Can patients evaluate the quality of hospital care? Med Care Rev, 47(3), 267-326.

Simon, T. D., Cawthon, M. L., Popalisky, J., \& Mangione-Smith, R. (2017). Development and Validation of the Pediatric Medical Complexity Algorithm (PMCA) Version 2.0. Hosp Pediatr, 7(7), 373-377. doi:10.1542/hpeds.2016-0173

Simon, T. D., Whitlock, K. B., Haaland, W., Wright, D. R., Zhou, C., Neff, J., . . Mangione-Smith, R. (2017). Effectiveness of a Comprehensive Case Management Service for Children With Medical Complexity. Pediatrics, 140(6). doi:10.1542/peds.2017-1641

Sitzia, J., \& Wood, N. (1997). Patient satisfaction: a review of issues and concepts. Soc Sci Med, 45(12), 18291843.

Srivastava, R., Downie, J., Hall, J., \& Reynolds, G. (2016). Costs of children with medical complexity in Australian public hospitals. Journal of Paediatrics and Child Health, 52(5), 566-571. doi:10.1111/jpc.13152

Stephens, L., Mountford, N., \& Bryan, D. (2015). Simplifying complex care - a pilot. Retrieved from http://www.rch.org.au/complex care/pilot-program/

Ziring, P. R., Brazdziunas, D., Cooley, W. C., Kastner, T. A., Kummer, M. E., Gonzalez de Pijem, L., ... Perrin, J. M. (1999). American Academy of Pediatrics. Committee on Children With Disabilities. Care coordination: integrating health and related systems of care for children with special health care needs. Pediatrics, 104(4 Pt 1), 978-981. 
TABLES

Table 1. Primary Caregiver Characteristics

\begin{tabular}{|c|c|}
\hline Primary Caregiver Characteristics & $n=53(\%)$ \\
\hline \multicolumn{2}{|l|}{ Primary Carer } \\
\hline Mother & $47(92.2)$ \\
\hline Father & $2(3.9)$ \\
\hline Other & $2(3.9)$ \\
\hline Missing & $2(3.9)$ \\
\hline Age in years (median, IQR) & $37(33-41)$ \\
\hline \multicolumn{2}{|l|}{ Relationship status } \\
\hline Married & $36(67.9)$ \\
\hline Defacto & $5(9.4)$ \\
\hline Single & $12(22.6)$ \\
\hline \multicolumn{2}{|l|}{ Main language spoken at home } \\
\hline English & $40(75.5)$ \\
\hline Urdu & $4(7.6)$ \\
\hline Turkish & $2(3.8)$ \\
\hline Arabic & $1(1.9)$ \\
\hline Hakha chin & $1(1.9)$ \\
\hline Mandarin & $1(1.9)$ \\
\hline Punjabi & $1(1.9)$ \\
\hline Sinhalese & $1(1.9)$ \\
\hline Swahili & $1(1.9)$ \\
\hline Missing & $1(1.9)$ \\
\hline \multicolumn{2}{|l|}{ Level of Education } \\
\hline No schooling completed & $2(3.9)$ \\
\hline Secondary school & $9(17.0)$ \\
\hline Trade/vocational training & $16(30.2)$ \\
\hline Degree & $26(49.1)$ \\
\hline \multicolumn{2}{|l|}{ Employment status } \\
\hline Employed for wages (including self-employed) & $15(28.3)$ \\
\hline Not employed (including housewife and full-time carer) & $38(71.7)$ \\
\hline Missing & $1(1.9)$ \\
\hline \multicolumn{2}{|l|}{ SEIFA quintiles of disadvantage } \\
\hline 1 (greatest disadvantage) & $10(18.9)$ \\
\hline 2 & $8(15.1)$ \\
\hline 3 & $5(9.4)$ \\
\hline 4 & $17(32.1)$ \\
\hline 5 (least disadvantage) & $11(20.8)$ \\
\hline Missing & $2(3.8)$ \\
\hline
\end{tabular}

IQR, interquartile range; SEIFA, Socio-Economic Indexes for Areas 
Table 2. Child Characteristics

\begin{tabular}{|c|c|}
\hline Child Characteristics & $n=53(\%)$ \\
\hline \multicolumn{2}{|l|}{ Gender } \\
\hline Female & 21 (39.6) \\
\hline \multicolumn{2}{|l|}{ Birth order } \\
\hline $1^{\text {st }}$ born & $26(49.1)$ \\
\hline $2^{\text {nd }}$ born & $18(34.0)$ \\
\hline $3^{\text {rd }}$ born & $6(11.3)$ \\
\hline $4^{\text {th }}$ born & $3(5.7)$ \\
\hline \multicolumn{2}{|l|}{ Age (years) } \\
\hline$<1$ & $4(7.6)$ \\
\hline $1-4$ & $28(52.8)$ \\
\hline $5-9$ & $16(30.2)$ \\
\hline $10-14$ & $4(7.6)$ \\
\hline $15-18$ & 0 \\
\hline$>18$ & $1(1.9)$ \\
\hline
\end{tabular}

This article is protected by copyright. All rights reserved. 
Table 3. Child Problem List*

\begin{tabular}{lc}
\hline Problems by System & frequency \\
\hline Gastroenterology & 89 \\
Neurology & 70 \\
Respiratory & 47 \\
Cardiology & 31 \\
Orthopaedic & 28 \\
Developmental & 28 \\
Genetic & 20 \\
Nephrology/urology & 20 \\
Ophthalmology & 19 \\
Otolaryngology & 14 \\
Endocrinology & 10 \\
Haematology/lmmunology & 10 \\
Metabolic & 5 \\
Plastics & 4 \\
Oncology & 3 \\
Dental & 3 \\
Allergy & 2 \\
Dermatology & 2 \\
\hline
\end{tabular}

\begin{tabular}{lc}
\hline Medical Technology Dependence & \\
\hline Gastrostomy/feeding tube & 32 \\
Tracheostomy & 9 \\
Home enteral nutrition & 8 \\
Home oxygen & 8 \\
Central line & 4
\end{tabular}

\begin{tabular}{lclc}
\hline Problems by Diagnosis & $n=53(\%)$ & & $n=53(\%)$ \\
\hline Feeding Problems & $32(60.4)$ & Cranial nerve palsy & $4(7.5)$ \\
Other Cardiac Lesions & $19(35.8)$ & Food allergy & $4(7.5)$ \\
Developmental difficulties & $17(30.1)$ & Recurrent UTIs & $4(7.5)$ \\
Cerebral Palsy & $17(30.1)$ & Apnoea & $4(7.5)$ \\
GORD & $15(28.3)$ & Sleep problems & $4(7.5)$ \\
Seizures & $15(28.3)$ & Osteopenia & $3(5.7)$ \\
Visual impairment & $14(26.4)$ & Chronic liver disease & $3(5.7)$ \\
Hip dysplasia and complications & $12(22.6)$ & Vertebral anomaly & $3(5.7)$ \\
TOF-OA/oesophageal stricture & $11(20.8)$ & Lower limb contractures & $3(5.7)$ \\
Obstructive sleep apnoea & $11(20.8)$ & Scoliosis & $3(5.7)$ \\
Structural airway obstruction & $10(18.9)$ & Craniosynostosis & $3(5.7)$ \\
Constipation & $9(17)$ & Intellectual disability & $3(5.7)$ \\
Anorectal malformation & $9(17)$ & Hypersalivation & $2(3.8)$ \\
Undiagnosed syndrome & $9(17)$ & Microcephaly & $2(3.8)$ \\
Complex congenital heart & $9(17)$ & Hyperglycaemia & $2(3.8)$ \\
disease & & Neutropenia & $2(3.8)$ \\
GORD requiring fundoplication & $8(15.1)$ & Undescended testes & $2(3.8)$ \\
Congenital limb malformation & $8(15.1)$ & Goldenhar syndrome & $2(3.8)$ \\
Congenital renal anomalies & $7(13.2)$ & Pierre Robin sequence & $2(3.8)$ \\
Failure to thrive & $6(11.3)$ & Immune deficiency & $2(3.8)$ \\
Hearing impairment & $6(11.3)$ & Astrocytoma & $2(3.8)$ \\
Hypotonia & $5(9.4)$ & Intra-ventricular haemorrhage & $2(3.8)$ \\
Chronic Lung Disease & $5(9.4)$ & Movement disorder & $2(3.8)$ \\
Congenital brain malformation & $5(9.4)$ & Tethering of spinal cord & $2(3.8)$ \\
& & & \\
& & &
\end{tabular}


BiPAP, bilevel positive airway pressure; GORD, gastro oesophageal reflux disease; TOF-OA, Tracheo Oesophageal Fistula-Oesophageal Atresia; UTI, Urinary Tract Infection; 
Table 4. Contact with the CCS

\begin{tabular}{l|c}
\hline Types of contact with CCS** & $n=53(\%)$ \\
Phone contact & $53(100)$ \\
Written, including email & $50(94.3)$ \\
Attendance at medical appointments & $51(96.2)$ \\
Family meetings & $23(43.4)$ \\
Other (including SMS, fellow review) & $2(3.7)$ \\
Frequency of contact with CCS & $1(1.9)$ \\
Daily & $25(47.2)$ \\
Weekly & $16(30.2)$ \\
Monthly & $11(20.8)$ \\
A few occasions & - \\
Once only & - \\
None & -
\end{tabular}

This article is protected by copyright. All rights reserved. 
Table 5. Themes

\begin{tabular}{|c|c|c|}
\hline Theme & Subtheme & Caregiver quote \\
\hline \multirow[t]{4}{*}{ Coordination } & $\begin{array}{l}\text { Appointment } \\
\text { coordination }\end{array}$ & $\begin{array}{l}\text { "...But the best thing is the co-ordination of appointments...so I'm } \\
\text { not there every day." }\end{array}$ \\
\hline & Streamlining care & $\begin{array}{l}\text { "...taking the stress out of her last hospital admission by } \\
\text { coordinating everything for us and having the doctors check her } \\
\text { straight away. I cannot express how much these actions lifted the } \\
\text { load of my shoulders." }\end{array}$ \\
\hline & $\begin{array}{l}\text { Single point of } \\
\text { contact }\end{array}$ & $\begin{array}{l}\text { "Having someone to call when my child becomes unwell to discuss a } \\
\text { plan on what to do has become something that I rely heavily on." }\end{array}$ \\
\hline & Overview role & $\begin{array}{l}\text { "Fills in the gaps of things that can get missed, by the many } \\
\text { specialists." }\end{array}$ \\
\hline \multirow[t]{2}{*}{ Communication } & Staff to caregiver & $\begin{array}{l}\text { "They listen to me. Before [CCS] they used to ignore me. Now I feel } \\
\text { heard. They take me seriously. My son nearly died so many times." }\end{array}$ \\
\hline & $\begin{array}{l}\text { Between } \\
\text { professionals }\end{array}$ & $\begin{array}{l}\text { "Living in a rural area and going to the local emergency } \\
\text { department, the [doctors] and paediatrician now have a team to } \\
\text { call to gather information on how to best treat my child in an acute } \\
\text { emergency. This has become an extremely valuable part of his } \\
\text { care." }\end{array}$ \\
\hline \multirow[t]{3}{*}{ Family Centred } & Reducing stress & $\begin{array}{l}\text { "I make one call or email regarding issues [and] the stress of } \\
\text { managing my child is reduced." } \\
\text { "Before the service we really struggled... It has given us piece of } \\
\text { mind." }\end{array}$ \\
\hline & Relationships & $\begin{array}{l}\text { "If you got too many families I would worry about the close } \\
\text { relationships with the complex care team be affected which is what } \\
\text { makes the team so amazing." }\end{array}$ \\
\hline & Advocacy & "negotiate things at medical appointments" \\
\hline \multirow[t]{4}{*}{ Quality care } & Availability & $\begin{array}{l}\text { "They have also been able to help us keep our son's health on track } \\
\text { and the best it can be. Giving us the opportunity to get on top of } \\
\text { things early with a quick phone call or text. It has also helped with } \\
\text { my stress levels and frustrations with the hospital and led to no } \\
\text { contact with the consumer liaison officer like I previously did." }\end{array}$ \\
\hline & Trust & $\begin{array}{l}\text { "They know what they're talking about. My son is complicated and } \\
\text { it's good to work with someone who knows your child and who } \\
\text { knows what they're talking about. I trust what they say." }\end{array}$ \\
\hline & Professional & \\
\hline & & $\begin{array}{l}\text { "I am extremely grateful that we are under this team, just knowing } \\
\text { they are a phone call away when we are in trouble has been life } \\
\text { changing for us." }\end{array}$ \\
\hline \multirow[t]{3}{*}{ Access } & 24-hour access & \\
\hline & Availability & $\begin{array}{l}\text { "Sometimes I'm worried that I'm taking up too much of their time, } \\
\text { as the complex care nurses can be very busy with other families. So } \\
\text { perhaps more staff so that they are not as busy." }\end{array}$ \\
\hline & Increase access & $\begin{array}{l}\text { "...my life would have been so much easier if Complex care existed } \\
\text { when my son was first born. Connecting NICU parents with the } \\
\text { complex care team before discharge would be amazing." }\end{array}$ \\
\hline
\end{tabular}




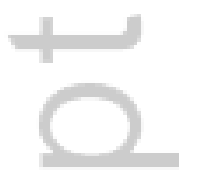


Figure 1. Caregiver reported satisfaction with the CCS

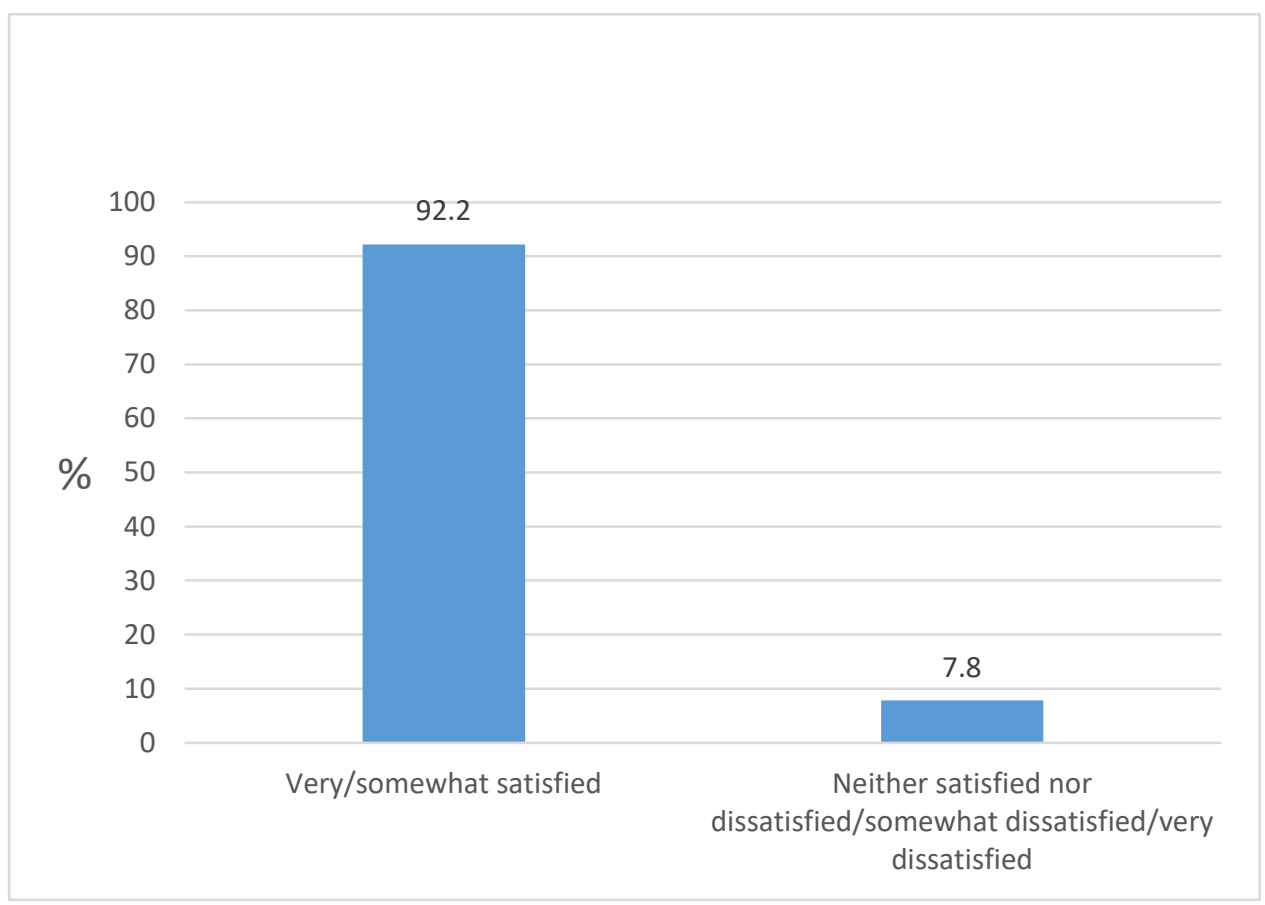

This article is protected by copyright. All rights reserved. 
Figure 2. The value of the components of the CCS to caregivers

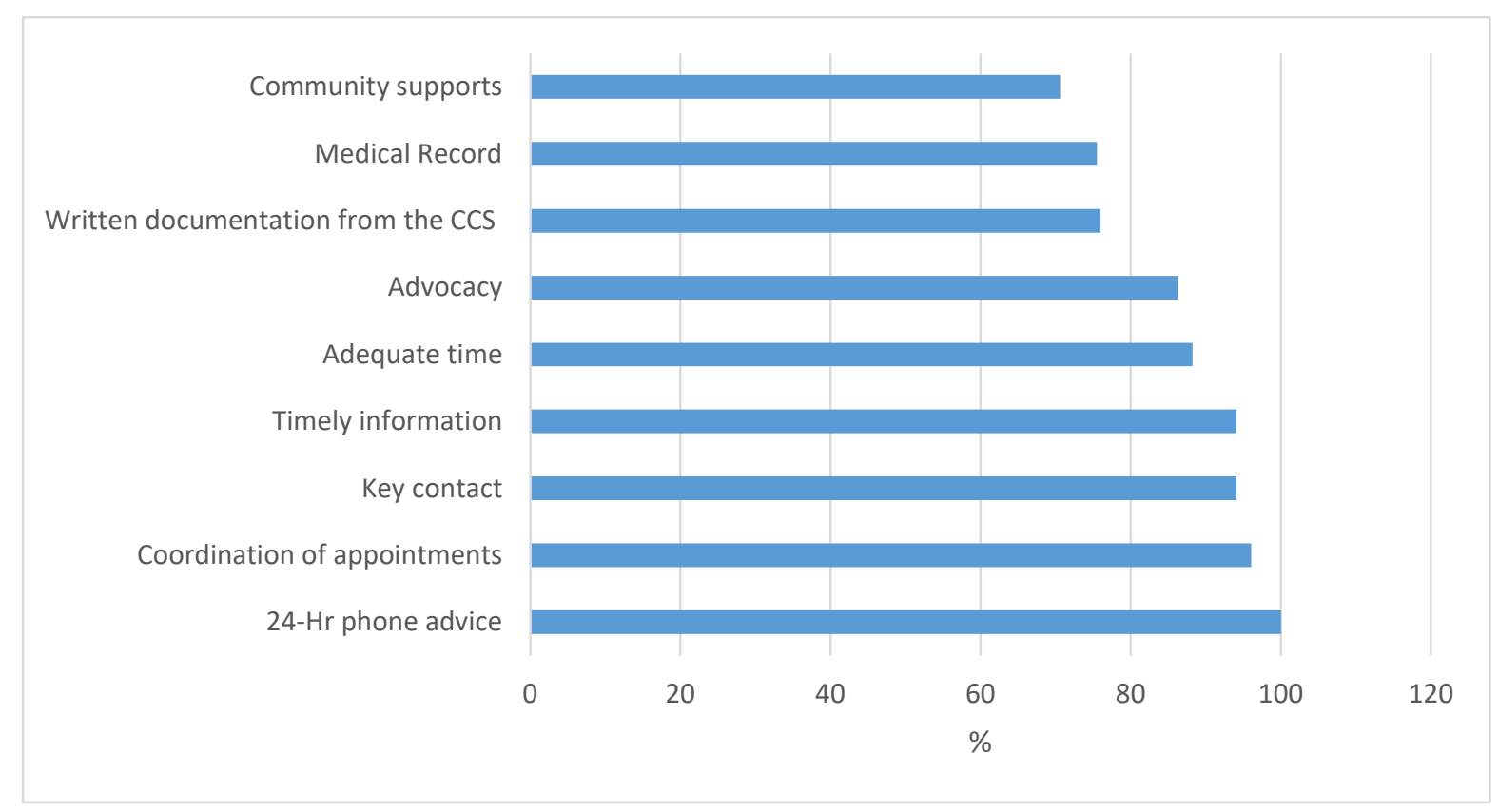

This article is protected by copyright. All rights reserved. 


\section{University Library}

\section{- M M N E R VA A gateway to Melbourne's research publications}

Minerva Access is the Institutional Repository of The University of Melbourne

\section{Author/s:}

D'Aprano, A;Gibb, S;Riess, S;Cooper, M;Mountford, N;Meehan, E

Title:

Important components of a programme for children with medical complexity: An Australian perspective

Date:

2020-01-01

\section{Citation:}

D'Aprano, A., Gibb, S., Riess, S., Cooper, M., Mountford, N. \& Meehan, E. (2020). Important components of a programme for children with medical complexity: An Australian perspective. CHILD CARE HEALTH AND DEVELOPMENT, 46 (1), pp.90-103. https:// doi.org/10.1111/cch.12721.

Persistent Link:

http://hdl.handle.net/11343/276824 